\title{
Anticipation of the Development of Job Satisfaction-Construct and Validation Results of an Indicator for Well-Being at the Workplace
}

\author{
Paul Jiménez, Anita Dunkl, Regina Stolz \\ Work, Organizational and Environmental Psychology, Institute of Psychology, University of Graz, Graz, Austria \\ Email: paul.jimenez@uni-graz.at
}

Received 7 April 2015; accepted 9 June 2015; published 12 June 2015

Copyright (C) 2015 by authors and Scientific Research Publishing Inc.

This work is licensed under the Creative Commons Attribution International License (CC BY). http://creativecommons.org/licenses/by/4.0/

(c) (7) Open Access

\begin{abstract}
In recent research on job satisfaction, the aspect of time and dynamics is gaining more and more attention. The Anticipation of the Development of Job Satisfaction (AD) is seen as a concept that looks at the estimations concerning the development of job satisfaction facets in the future. More specifically, as job satisfaction can be seen as an indicator for well-being, AD can be regarded as the estimation of future well-being at the workplace. The aim of this study is to present this construct and to investigate whether it can be empirically separated from related constructs. Therefore, the influences of certain state and trait characteristics connected to well-being were in the focal point of this study. In particular, the influences of job satisfaction, life satisfaction, learned helplessness, the core self-evaluations and state anxiety on anticipation of development of job satisfaction were analysed. The study was made in an Austrian institution of higher education with 213 employees participating. The results of structural equation modelling showed that the level of anticipation of the development of job satisfaction was a significant predictor for job satisfaction. Furthermore, satisfying indicators for discriminant validity to other regarded constructs could be found.
\end{abstract}

\section{Keywords}

Anticipation of the Development of Job Satisfaction, Job Satisfaction, Discriminant Validity, Core Self-Evaluations, Structural Equation Modelling

\section{Introduction}

Well-being in the organizational context can be difficult to define, as "well-being” can be used in a very general

How to cite this paper: Jiménez, P., Dunkl, A., \& Stolz, R. (2015). Anticipation of the Development of Job SatisfactionConstruct and Validation Results of an Indicator for Well-Being at the Workplace. Psychology, 6, 856-866. 
manner. Job satisfaction can be seen as one of the oldest, most common operationalizations of well-being at the workplace (Wright, 2014; Wright \& Bonnet, 2007) and is often defined as the positive emotional state or reaction towards work (Connolly \& Viswesvaran, 2000; Judge \& Larsen, 2001). As an important indicator for employee well-being, job satisfaction is also regularly evaluated in workplace health promotion projects (Birdee et al., 2013; Milner et al., 2013) and is highly correlated with employee health, performance, absenteeism and intention to quit (Faragher, Cass, \& Cooper, 2005; Iaffaldano \& Muchinsky, 1985; Inauen, Jenny, \& Bauer, 2015; Tzeng, 2002; Wegge, Schmidt, Parkes, \& van Dick, 2007). Nevertheless if job satisfaction and other variables are used as a basis in workplace health promotion projects then a gap can be recognized as dynamic aspects and the factor "time" are not included (Roe, 2008). The concept of the anticipation of the development of job satisfaction (AD) wants to fill that gap. This study introduces the concept and presents first validation results of AD as an indicator for well-being at the workplace.

Job satisfaction (as other variables) can only partly predict an outcome like performance (see e.g. Bowling, 2007; Judge Thoresen, Bono, \& Patton, 2001); this is true for other behaviour outcomes as well. e.g. for predicting turnover with job satisfaction then also the economic situation has to be considered (Semmer, Baillod, Stadler, \& Gail, 1996; Spector, 2000). These external aspects also represent the point of a changing working environment and are therefore depending on the factor time. In the domain of job satisfaction the aspect of time and dynamics represent important factors. Although the importance of the consideration of timing issues in applied psychology has already been discussed by different authors (especially by Roe, 2008), job satisfaction models in general do not include this approach.

Considering job satisfaction as an emotional response in the working context, it is particularly important to conceptualize job satisfaction as a dynamic process (Fischer \& Belschak, 2006; Fischer, Fischer, \& Meyenschein, 2013). Emotional responses are caused by both states and traits; therefore, an individual's emotional state at work is also dependent on situational factors at the workplace. This emotional state can be regulated downwards or upwards, again depending on situational factors or trait characteristics, and this emotion regulation changes the subjective job satisfaction (Fischer et al., 2013). Dynamic models like that from Büssing \& Bissels (1998) include time in the sense that the satisfaction level is seen as an output and at the same time as an input for coping strategies to reach an acceptable level of job satisfaction. The feedback model of job satisfaction of Jiménez $(2000,2002,2006)$ suggests that the adaption of the aspiration level of job satisfaction is set by estimating the development of further job satisfaction. To explain changes of behaviour and action orientation in time it is necessary to look at the estimations concerning the development of job satisfaction facets in the future as an additional aspect. Previous studies (Jiménez \& Topf, 2007) show that the anticipation of the development of job satisfaction (AD) is able to explain work-relevant behaviour. The objective of the current study is to differentiate the construct "anticipation of development of job satisfaction" from other constructs that are related to well-being.

By defining job satisfaction as an indicator for well-being, $\mathrm{AD}$ can be regarded as the estimation of future well-being at the workplace. e.g. a person expects that the working conditions will improve, and also anticipates that the development of job satisfaction will get better in the future (then well-being will be expected to be the same or better in the future.) That also means that there is no need for further action. So the anticipation of development of job satisfaction includes expected changes in time and is seen as an addition to the evaluation of the current state of the work place (in the form of job satisfaction). Looking at other models the construct of AD can be differentiated.

The Valence-Instrumentality-Expectancy theory of Vroom (1964) describes three factors that have an influence on people's motivation and, consequently, on their behaviour and action orientation. Besides valence and instrumentality, expectancy plays a central role in the motivational process. Results of former behaviour can influence future behaviour through positive or negative valences (extent to which expected outcomes are attractive/ unattractive). If there are different alternatives for behaviour, the valence of each alternative in combination with the instrumentality (subjective perception if a result of an effort brings desirable further results) of this specific alternative, are multiplied and the result is the "total valence". The expectancy that effort will lead to a certain level of performance is multiplied with the (total) valence. Studies like Van Eerde and Thierry (1996) found moderate correlations between Vroom's model and effort, intention and performance in their meta-analysis. The expectancy aspect in this model means the expected outcome and wants to explain why and how people choose their coping strategy. 


\section{Changes in Time and Anticipating Different Aspects}

The anticipation of development then assumes the view of persons looking at possible future changes. This supplements the models of job satisfaction and adds a dynamic aspect. Roe (2003) also suggests that the aspect of time in the work context has to be included to understand the dynamic aspects of behaviour and to predict behaviour out of the current state.

A differentiated proposal is to use more than global values and to measure facets of job satisfaction to get better predictions (e.g. Semmer et al., 1996; Jiménez, 2002). Based upon that, the AD is understood as a function of job satisfaction and therefore measures the estimation of different facets of job satisfaction.

As with job satisfaction, AD has to be examined to differentiate it from other similar constructs, as it is not only influenced by job satisfaction but also by situational and dispositional factors. By considering AD as the estimation of future well-being at the workplace, then AD has to be compared with other indicators of wellbeing to distinguish $\mathrm{AD}$ from other constructs. The current paper looks at these special aspects for discriminant validity. The constructs for validation shall be described in the next section.

\subsection{Core Self-Evaluations}

Judge, Locke and Durham (1997) describe the concept “Core Self-Evaluations” (CSE) as a (broad) trait that consists of four separate constructs: Self-esteem, Generalized Self-Efficacy, Neuroticism and Internal Locus of Control. Judge et al. (Judge, Bono, \& Locke, 2000; Judge, Locke, Durham, \& Kluger, 1998) found out that the four constructs belong to one factor. Hence, all the separate constructs describe one self-evaluative, global and wide trait (Judge et al., 1997). As the temporal stabilities of the separate constructs of the Core-Self-Evaluations are sufficient, the assumption that those are indicators for one mutual trait is justified (Dormann, Fay, Zapf, \& Frese, 2006). Judge et al. (1998, 2000) could prove that Core-Self-Evaluations have an effect on job satisfaction and life satisfaction. Judge and Bono (2001) could also confirm moderate positive correlations between the four core-self-evaluation-traits and job satisfaction and, furthermore, with performance.

\subsection{Learned Helplessness}

The phenomenon Learned Helplessness is described by (Seligman, 1975; Abramson, Seligman, \& Taesdale, 1978) as an experienced helplessness of people or animals that occurs although, in an objective point of view, a situation can be influenced. If helplessness is continuously experienced in specific situations, there is a risk that helpless behaviour is learned by people. Learned Helplessness occurs if incidents seem to be uncontrollable for a person and helpless people tend not to do anything to change a negative situation. Judge and Bono (2001) expect that Learned Helplessness has an effect on job satisfaction and performance at work. Carlson \& Kacmar (1994) take Learned Helplessness as a predictor for performance and effort in the work context. It is also confirmed that Learned Helplessness is often accompanied by a low self-esteem in the case of unemployment (Garcia Rodriguez, 1997). As self-esteem is a part of the Core-Self-Evaluations, it is expected that there is a negative relation between Learned Helplessness and Core-Self-Evaluations.

\subsection{Satisfaction with Life}

Diener (1994) defines Satisfaction with Life as an aspect of subjective well-being. It consists of two components - an affective and a cognitive part. In case of subjective well-being, the affective component includes positive emotions and the absence of negative affects. The cognitive part of subjective well-being means personal anticipation for one's life. Therefore, a standard for comparison is consulted, which can be inside a person or extern (for example comparison with friends). Eid \& Diener (2004) describe satisfaction with life as very stable. Job satisfaction can be seen as a predictor of satisfaction with life (Judge et al., 1998; Judge, Jackson, Shaw, Scott, \& Rich, 2007), although job satisfaction does usually not include components of the individual's like outside of work. Nevertheless, both aspects, satisfaction with life and job satisfaction, are seen as important indicators for well-being (Chen, Ai, \& You, 2014; Wright, 2014).

\subsection{State Anxiety}

As in studies of Dormann \& Zapf (2001) and Dormann et al. (2006) it could be confirmed that the majority of 
the variances of job satisfaction can be attributed to states, state anxiety should also be taken into consideration within this context. According to the mentioned studies traits have less influence on job satisfaction than states. Niklas and Dormann (2005) found that state affect has an influence on job satisfaction even if trait affect and trait job satisfaction are controlled. In many studies the relation between state or trait anxiety and job satisfaction or anxiety as a moderating variable between core dimensions of the job and outcome variables is confirmed (Parmar, 2001; Sánchez-Anguita, Conde, De la Torre, \& Pulido, 2008).

\section{Research Question and Hypotheses}

The concept anticipation of the development of job satisfaction (AD) describes the anticipated development of different facets of job satisfaction and can be seen as an indicator for the anticipation of future well-being at the workplace. It describes the anticipation of possible changes in job satisfaction, in which the aspect of time (Roe, 2003, 2008) is important. This dynamic view of job satisfaction has not been fully investigated in past research, but is favoured in more current views of job satisfaction (Fischer et al., 2013). Vroom's (1964) Valence-Instrumentality-Expectancy theory supports the idea of the function of variables (valence, instrumentality, expectancy) on developing intentions and decisions for behaviour. That is also a basic idea of AD. With the aim to differentiate the construct in this study there is the question which trait- and state-aspects have an influence on AD. Simultaneously, it is interesting to investigate if the construct can be differentiated from other similar concepts.

Based on past research, following hypotheses are postulated:

- It is postulated, that Learned Helplessness is negatively related to AD.

- It is assumed that satisfaction with life is positively correlated with job satisfaction (Judge et al., 1998; Judge et al., 2007) as well as with AD.

- It is hypothesized that state anxiety is negatively correlated with job satisfaction (Parmar, 2001; SánchezAnguita et al., 2008), and also to AD.

- As the current job satisfaction is assumed to be a predictor for future job satisfaction, it is also assumed that job satisfaction is positively related to AD.

- It is hypothesized that Core Self-Evaluations are in a positive relation with life satisfaction and job satisfaction, which are indicators for well-being (Judge et al., 1998, 2000; Judge \& Bono, 2001).

- It is also expected that Core Self-Evaluations correlate negatively with Learned Helplessness, based on the study of Garcia Rodriguez (1997).

- Furthermore, a positive relation between Core Self-Evaluations and AD is expected.

To summarize all hypotheses, a hypothesized model is postulated (Figure 1). It is assumed that the theoretical covariance matrix corresponds with the empirical covariance matrix.

\section{Method}

\subsection{Participants and Procedure}

The sample for the study consists of employees of an Austrian institution of higher education. The study was introduced as a scientific research of factors associated with job satisfaction. The online survey was supported by the works council and the response to the survey therefore was intended to take place within the working hours.

All 1367 employees of this institution of higher education were invited to contribute to the online study not only with the goal to provide data for scientific research but also to use the possibility to give feedback about their working situation. The participation was voluntary. The survey was available for all employees via an online platform. Out of all invited employees 243 people participated-so the response rate is $17.8 \%$. Among the internal staff, people working constantly within the institution's building and therefore having a closer relation to the employer and the working environment, the response rate of $44 \%$ was significantly higher compared to the external employees (3.8\%). Out of the 243 participants, 213 completed the entire questionnaire and these data are considered in the statistical analysis.

$55.5 \%$ of these 213 surveyed employees are male. $33.7 \%$ are between 26 - 35 years, while $37 \%$ are among the 36 - 45 year old employees. $26 \%$ of the surveyed employees work two to five years and $23.6 \%$ work 5 - 8 years in this organisation.

The majority of the sample works in the area of teaching and research (67.6\%), 32.4\% in administration and $8.2 \%$ in the field of medical technical service. 


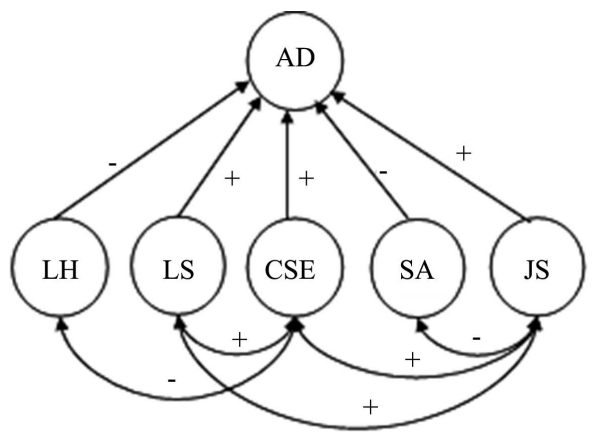

Figure 1. Hypothesized structural model. Note: -: expected negative correlation/regression weight, +: expected positive correlation/regression weight; Abbreviations: JS - job satisfaction, AD — anticipation of the development of job satisfaction, LH-learned helplessness, LS-life satisfaction, CSE-core self-evaluations, SA—state anxiety.

\subsection{Measures}

Job Satisfaction. With the Profile Analysis of Job Satisfaction (PAJS, Jiménez, 2008), job satisfaction is measured in 11 facets of work life with 3 to 5 items (the form of 39 items was used in this study). The items can be answered on a 5-point-Likert-scale ranging from 1 (satisfied) to 5 (dissatisfied). The facets can be clustered into three areas (organisational, social and the work environment). Studies show a Cronbach Alpha of the facets from .82 to .91 . For an easier interpretation of the results, high values within this scale refer to high job satisfaction.

Anticipation of the Development of Job Satisfaction $(A D)$. This scale is part of the survey system of PAJS (Jiménez, 2008) and is presented in the questionnaire directly after the items of the PAJS. For every facet of job satisfaction (e.g., information, career, colleagues, decision range) the $\mathrm{AD}$ is asked in this questionnaire. The answer scale ranges from 1 (very positive) to 5 (very negative). The scale consists of 16 items which can be clustered too into three areas (Jiménez \& Topf, 2007). The total score was used for this study (Cronbach Alpha is .89). Again, for an easier interpretation of the results, high values within this scale refer to high AD.

Core Self-Evaluations. For the measurement of the core self-evaluations the 12-item German version of the Core Self-Evaluations Scale (CSES) from Stumpp, Muck, Hülsheger, Judge, \& Maier (2010) was used. Responses are based on a 1 (strongly disagree) to 5 (strongly agree) scale (Cronbach Alpha is .86). One central value can be calculated out of the items.

Life Satisfaction. Schumacher's German version (2003) of the 5-item Satisfaction with life Scale (SWLS) was used to measure life satisfaction. Responses are based on a 1 (strongly agree) to 7 (strongly disagree) scale (Cronbach Alpha is .88). In the following, for an easier understanding of the results, high values within this scale refer to high life satisfaction.

Learned Helplessness. The construct of Learned Helplessness was measured with the HOM-Scale of the HAKEMP-90 (Kuhl, 1990; Cronbach Alpha is .75). These 12 Items, describing different situations, allow measuring the action orientation of a person in a situation of failure.

State Anxiety. The German version of the state scale X-1 of the State-Trait Anxiety Inventory (STAI, Laux, Glanzmann, Schaffner, \& Spielberger, 1981) was used. This 20 item scale quantifies the level of present anxiety using questions concerning the temporary physical and psychical condition. The use of this scale allows evaluating how respondents feel right now at the moment of the survey. Responses are based on 1 (not at all) to 4 (very much so) scale (Cronbach Alpha is .90).

Descriptive statistics and scale reliabilities of the questionnaires are displayed in Table 1.

\section{Results}

\subsection{Statistical Analyses}

Structural equation modelling was chosen as statistical procedure. Therefore the data were coded and processed using besides SPSS (version 15.0) for descriptive analysis also the program AMOS (version 7.0) for structural 
Table 1. Descriptive statistics, scale reliabilities and correlations $(\mathrm{n}=213)$.

\begin{tabular}{|c|c|c|c|c|c|c|c|c|c|}
\hline Variable & M & SD & $\alpha$ & $\mathrm{AD}$ & JS & SA & CSE & LS & $\mathrm{LH}$ \\
\hline $\begin{array}{l}\text { Anticipation of development of job } \\
\text { satisfaction (AD) }\end{array}$ & 2.88 & .56 & .90 & & & & & & \\
\hline Job satisfaction (JS) & 2.35 & .53 & .72 & $.66^{* *}$ & & & & & \\
\hline State anxiety (SA) & 1.85 & .48 & .92 & $-.24^{* *}$ & $-.40^{* *}$ & & & & \\
\hline Core self-evaluations (CSE) & 4.10 & .60 & .89 & .07 & $.18^{* *}$ & $-.44^{* *}$ & & & \\
\hline Life satisfaction (LS) & 2.47 & .99 & .72 & $.18^{* *}$ & $.32^{* *}$ & $-.44^{* *}$ & $.47^{* *}$ & & \\
\hline Learned helplessness $(\mathrm{LH})^{+}$ & - & - & .76 & -.01 & -.02 & $.30^{* *}$ & $-.43^{* *}$ & $-.20^{* *}$ & - \\
\hline
\end{tabular}

Note: ${ }^{* *} p<0.01$. ${ }^{+}$Due to the dichotomous scale of the HAKEMP-90 for measuring learned helplessness, descriptive statistics are not included in the table.

equation modelling. Within the analysis, Maximum likelihood estimation was used.

The main objective - to test discriminant and convergent validity of AD—was accomplished in two steps. After testing the assumptions of structural equation modelling regarding the quality of the data, first, the single measurement models of each construct included in the hypothesized structural model were analysed and if necessary modified to reach adequate fit indices. Second, the structure between the latent factors and their fit concerning the hypothesized model was calculated. For both steps of structural equation modelling AMOS was used to test whether the hypothesized relations between the construct could be found in the empirical structure of the data.

In principle, within these analyses manifest variables were based on the single items of each factor. Due to excessive free parameters as a result of the complexity of the models or the extent of required modification steps, in some cases single items finally were combined to subscales based on the existing structure of the construct or on the results of previous factor analyses when indicated. This was the case for the measurement models of AD, the core self-evaluations and state anxiety. The procedure regarding the modification steps in the structural and measurement models to achieve adequate fit-indices was based on fundamental literature (e.g. West, Finch, \& Curran, 1995; Schermelleh-Engel, Moosbrugger, \& Müller, 2003; Bühner, 2006).

To estimate the extent to which the hypothesized model is reflected by the measured covariance matrix and to ensure the quality of the final results, global fit measures like the Goodness-of-Fit-Index (GFI), the Adjusted Goodness-of-Fit-Index (AGFI), the Comparative Fit Index (CFI) as well as the Root-Mean-Square-Error-ofApproximation (RMSEA) and the Chi-square were evaluated.

According to Schermelleh-Engel, Moosbrugger, \& Müller (2003) and Bühner (2006) a non-significant ChiSquare, GFI-values above .95, AGFI-values above .95, CFI-values above .97 and a RMSEA-value under .05 reflect a good fit. The authors also consider GFI-values above .90, AGFI-values above .85, CFI-values above .90 and a RMSEA-value under .08 as reflection of an acceptable fit of the model to the data.

The results showed that all modified measurement models attain good or acceptable fit-indices, as shown in Table 2. The calculated manifest structure for the AD showed a good fit.

Furthermore, the modified structure between the regarded constructs mainly showed satisfying results as displayed in Table 3. Although the value of the GFI as well as of the AGFI was not satisfying, in combination with the sufficient sample size the non-significant Chi-Square indicated an exact fit of the model according to Bühner (2006).

The modified final structure between the latent constructs within the model and the calculated parameters are displayed in Figure 2. Due to discrepancies between the hypothesized structural model and the empirical results, not all assumed correlations or regression paths could be found in the data and therefore had to be removed from the model within the modification steps.

\subsection{Results for Hypotheses}

The hypothesized model in Figure 1 was partially supported. Not all of the assumed relations between the single constructs could be found in the data. The calculated statistical data showed that, contrary to the hypotheses, in particular no direct relation concerning $\mathrm{AD}$ and the constructs of Learned Helplessness, life satisfaction, core 


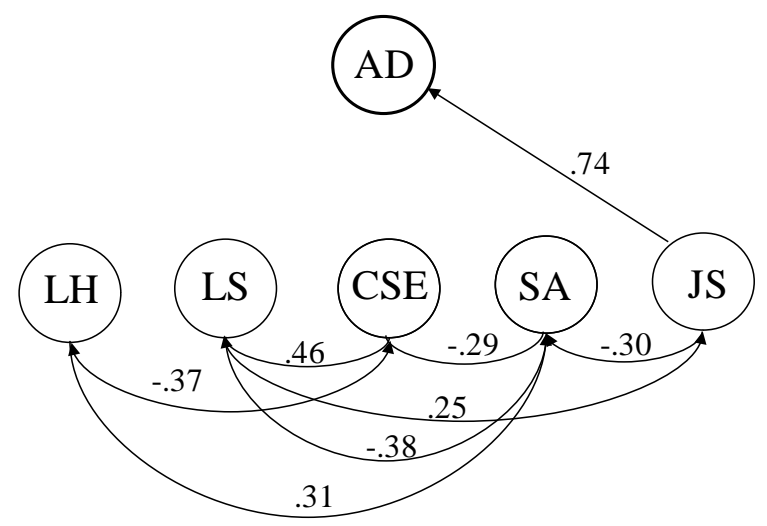

Figure 2. AMOS-results of the structural model. Note: standardised regression weight from JS to AD; other parameters are correlations; all parameters are significant at $p<0.01$. Abbreviations: JS—job satisfaction, AD—anticipation of the development of job satisfaction, LH-learned helplessness, LS-life Satisfaction, CSE—core self-evaluation, SA — state anxiety.

Table 2. AMOS-results of the modified measurement models.

\begin{tabular}{cccccccc}
\hline Measuring models & $\chi^{2}$ & $p$ & GFI & AGFI & CFI & RMSEA \\
AD & 2.24 & .12 & .99 & .95 & .99 & .08 \\
JS & 51.25 & .06 & .96 & .93 & .98 & .04 & .00 \\
CC & .06 & .80 & 1.00 & 1.00 & 1.00 & .99 & .09 \\
CSE & 2.81 & .09 & .99 & .94 & 1.00 & .00 \\
LS & .02 & .99 & 1.00 & 1.00 & 1.00 & .00 \\
LH & 57.18 & .07 & .95 & .93 & .95 & .04 \\
Total model & 708.77 & .15 & .85 & .82 & .95 & .04 \\
\hline
\end{tabular}

Note: Abbreviations: JS—job satisfaction, AD—anticipation of development of job satisfaction, LH—learned helplessness, LS—life satisfaction, CSE—core self-evaluation, CC—current condition.

Table 3. AMOS-results of the modified structural model.

\begin{tabular}{cccccccc}
\hline Indices & $\chi^{2}$ & $p$ & GFI & AGFI & CFI & RMSEA \\
\hline Fits & 720.36 & .14 & .85 & .82 & .95 & .04 \\
\hline
\end{tabular}

Note: JS—job satisfaction, AD—anticipation of development of job satisfaction, LH—learned helplessness, LS—life satisfaction, CSE—core selfevaluation, CC-current condition.

self-evaluations and state anxiety could be found. Unexpected significant correlations between Learned Helplessness and state anxiety $(r=.31)$ as well as between state anxiety and life satisfaction $(r=-.38)$ were found instead.

Hypothesized and statistically confirmed results referred to the correlations between Learned Helplessness and core self-evaluations $(r=-.37)$, life satisfaction and core self-evaluations $(r=.46)$, life and job satisfaction $(\mathrm{r}=.25)$ as well as between job satisfaction and state anxiety $(\mathrm{r}=-.30)$. Also the crucial significant standardised regression from job satisfaction to $\mathrm{AD}(\beta=.74)$ could be approved within the results of this study. Hence, an important part of the variance of the $\mathrm{AD}$ could be explained by job satisfaction $(\mathrm{SMC}=.55)$. As insinuated before, additional direct influences on AD by other considered constructs could not be found in the data.

\section{Discussion}

It was the intention to differentiate the construct AD from job satisfaction, Core-Self-Evaluations, Learned Hel- 
plessness, Satisfaction with life and state anxiety, as they include state-as well as trait aspects and can be regarded as indicators for well-being.

Among other results, the calculated manifest structure for AD showed good fits. Also the latent structure between the regarded constructs showed satisfying results (see Figure 2). The results confirmed the postulated direct relation from job satisfaction to $\mathrm{AD}$. An important part of the variance of the $\mathrm{AD}$ could be explained by job satisfaction. A person that is satisfied concerning the work context tends to have more positive estimations regarding the future development of her own job satisfaction and therefore also for her future well-being. It is obvious to look at this result with a critical eye-due to the direct relation from the new construct to job satisfaction-it could be argued that these constructs are redundant. However, the circumstance that many of the validation-constructs are in a close relation with job satisfaction, whereas none of them is related to the AD, has to be accentuated. These results support the assumption that the two constructs cannot be regarded as one: The construct "anticipation of development of job satisfaction" can be seen as a separate one although there is a high correlation with the current job satisfaction. The more people are content with their job, the more positive is their anticipation of development of job satisfaction.

As mentioned before, additional direct influences on AD through other considered constructs could not be found. Nevertheless, some of the validation-constructs were in an indirect relation with AD through job satisfaction that can be seen as a mediator variable. Moreover it could be possible that nonlinear relations exist. With the analysis method SEM, which was used in this study, such effects cannot be shown. Also causal effects would be interesting and are part of longitudinal studies which are under progress.

In this section, the results concerning relations between the validation-constructs shall be examined. Mainly, significant medium correlations could be found among the results. That is not surprising because of the conceptualization of involved variables. First, a negative relation between job satisfaction and state anxiety could be identified. The higher the state anxiety of a person is the higher is the dissatisfaction with work. Job satisfaction and life satisfaction were in a positive relation, according to the results. The outcome was expected like that.

The third hypothesized relation concerning job satisfaction and Core Self-Evaluations could not be confirmed in this study, compared to previous studies (Judge et al., 1998; Judge et al., 2000), in which Core Self-Evaluations consistently were a significant predictor of job satisfaction. Therefore a comparison of the values of CoreSelf-Evaluations of the current sample to other samples was made. Actually, the Core Self-Evaluations-value of the current sample $(M=3.88 ; N=243)$ was significantly higher than that of two other samples chosen for the comparison $(\mathrm{M}=3.82, \mathrm{SD}=.48, \mathrm{~N}=199 ; \mathrm{M}=3.65, \mathrm{SD}=.52, \mathrm{~N}=118$; data published in the study Stumpp et al., 2010). As Table 1—including results of descriptive statistics—shows, there is a significant relation between job satisfaction and Core Self-Evaluations which disappears when analysing with SEM. It can be concluded that in case of very high values of Core-Self-Evaluations, the relation of Core Self-Evaluations with job satisfaction or $\mathrm{AD}$ is low or cannot be found. The state aspects seem to be more important in this context than the trait aspects.

Various further hypothesized relations between validating constructs could be confirmed. A positive relation between Core Self-Evaluations and life satisfaction confirmed the results of Judge et al. (2007). Learned Helplessness correlated with Core-Self-Evaluations, as expected. As the Core-Self-Evaluations include the construct self-efficacy, which can be seen as the opposite pole of Learned Helplessness, the result is comprehensible. There are two more correlations that are interesting because they have not been expected. State anxiety was negatively related to Core Self-Evaluations. Hence, people who have higher values in their Core Self-Evaluations are less prone to state-anxiety. That makes sense, as people with higher Core Self-Evaluations have more effective strategies at their disposal to handle negative situations. Further, Learned Helplessness was negatively related to the construct Core Self-Evaluations, although not postulated in the hypotheses. Learned Helplessness is signified by lacking control mechanisms, therefore it is not surprising that it is accompanied by state-anxiety and missing well-being (referring to situations). The correlation between life satisfaction and state anxiety was not hypothesized but was in line with earlier findings (Glatzer, 1995).

The presented study analyses $\mathrm{AD}$ as a new construct which is distinct to other analysed constructs and variables and therefore shows discriminant validity. The major aspect of the results is that the expected correlations of $\mathrm{AD}$ to job satisfaction and the other constructs could be found only partially. The variables used for discrimination were selected as they could be seen as very similar to $A D$ in the sense that $A D$ could be a form of "optimism", i.e. aspects "included" in Core Self-Evaluations, Learned Helplessness, satisfaction with life or (negatively related) state anxiety. Also one could argue that $\mathrm{AD}$ is the same or very similar construct as job sa- 
tisfaction as the correlation between the two variables is high. In that case, AD should show relations to the other constructs in the model, which is not found in the present study. We therefore argue for a moderator effect which is in line with the proposed model of $\mathrm{AD}$ and job satisfaction. The results indicate important practical implications as $\mathrm{AD}$ can add predictive value to the relation between job satisfaction and work relevant behaviour.

\section{Conclusion and Further Steps for Anticipation of Development}

The important hypothesized relations between job satisfaction and state anxiety, life satisfaction could be found. As already mentioned the not found relation between job satisfaction and CSE must be explained with a relatively high value of CSE in that sample which can be possibly explained by a high education level and a high assumption of getting a comparable job (this measure is part of the employee survey) which is $50 \%$ better than the norm group. These aspects of the model therefore will be looked at again in a next study with much broader range of education level and age.

As a next step the additive predictive value of the concept of AD to job satisfaction has to be examined. It is of importance for basic and for applied research to know about this. A dynamic view of the working environment which includes the time aspects, too, can help to assess the action orientation of people at work. That helps to reassess the influential aspects of the work onto employees. With that knowledge it is possible to derive interventions to improve both economic aspects and well-being aspects of work. Especially for workplace health promotion programs it is important to include these action oriented concepts to influence the attitudes and the behaviours towards well-being and health.

\section{References}

Abramson, L. Y., Seligman M. E. P., \& Taesdale, J. D. (1978). Learned Helplessness in Humans: Critique and Reformulation. Journal of Abnormal Psychology, 87, 49-74. http://dx.doi.org/10.1037/0021-843X.87.1.49

Birdee, G., Byrne, D., McGown, P., Rothman, R., Rolando, L., Holmes, M., \& Yarbrough, M. (2013). Relationship between Physical Inactivity and Health Characteristics among Participants in an Employee Wellness Program. Journal of Occupational Environmental Medicine, 55, 514-519. http://dx.doi.org/10.1097/JOM.0b013e31827f37d7

Bowling, N. A. (2007). Is the Job Satisfaction-Job Performance Relationship Spurious? A Meta-Analytic Examination. Journal of Vocational Behavior, 71, 167-185. http://dx.doi.org/10.1016/j.jvb.2007.04.007

Bühner, M. (2006). Einführung in die Test- und Fragebogenkonstruktion (2. aktualisierte Auflage). München: Pearson Studium.

Büssing, A., \& Bissels, T. (1998). Different Forms of Work Satisfaction: Concept and Qualitative Research. European Psychologist, 3, 209-218. http://dx.doi.org/10.1027/1016-9040.3.3.209

Carlson, D., \& Kacmar, K. (1994). Learned Helplessness as a Predictor of Employee Outcomes: An Applied Model. Human Resource Management Review, 4, 235-256. http://dx.doi.org/10.1016/1053-4822(94)90014-0

Chen, G., Ai, J., \& You Y. (2014). Managerial Coaching Behaviours and Their Relations to Job Satisfaction, Life Satisfaction and Orientations to Happiness. Psychology, 2, 147-156. http://dx.doi.org/10.4236/jhrss.2014.23014

Connolly, J. J., \& Viswesvaran, C. (2000). The Role of Affectivity in Job Satisfaction: A Meta-Analysis. Personality and Individual Differences, 29, 265-281. http://dx.doi.org/10.1016/S0191-8869(99)00192-0

Diener, E. (1994). Assessing Subjective Well-Being: Progress and Opportunities. Social Indicators Research, 31, $103-157$. http://dx.doi.org/10.1007/BF01207052

Dormann, C., Fay, D., Zapf, D., \& Frese, M. (2006). A State-Trait Analysis of Job Satisfaction: On the Effect of Core SelfEvaluations. Applied Psychology: An International Review, 55, 27-51. http://dx.doi.org/10.1111/j.1464-0597.2006.00227.x

Dormann, C., \& Zapf, D. (2001). Job Satisfaction-A Meta-Analysis of Stabilities. Journal of Organizational Behavior, 22, 483-504. http://dx.doi.org/10.1002/job.98

Eid, M., \& Diener, E. (2004). Global Judgments of Subjective Well-Being: Situational Variability and Long-Term Stability. Social Indicators Research, 65, 245-277. http://dx.doi.org/10.1023/B:SOCI.0000003801.89195.bc

Faragher, E. B., Cass, M., \& Cooper, C. (2005). The Relationship between Job Satisfaction and Health: A Meta-Analysis. Journal of Occupational Environmental Medicine, 62, 105-112. http://dx.doi.org/10.1136/oem.2002.006734

Fischer, L., \& Belschak, F. (2006). Objektive Arbeitszufriedenheit? Oder: Was messen wir, wenn wir nach der Zufriedenheit mit der Arbeit fragen? (Objective Job Satisfaction? Or Else: What Do We Measure If We Ask about Satisfaction at Work?) In L. Fischer (Ed.), Arbeitszufriedenheit. Konzepte und empirische Befunde (pp. 80-108). Göttingen: Hogrefe.

Fischer, O., Fischer, L., \& Meyenschein, K. (2013). Emotion at Work. Wirtschaftspsychologie, 2/3-2013, 92-103. 
Garcia Rodriguez, Y. (1997). Learned Helplessness or Expectancy Value? A Psychological Model for Describing the Experiences of Different Categories of Unemployed People. Journal of Adolescence, 20, 321-332.

http://dx.doi.org/10.1006/jado.1997.0088

Glatzer, W. (1995). Quality of Life in Advanced Industrialized Countries: The Case of West Germany. In F. Strack, M. Argyle, \& N. Schwarz (Hrsg.), Subjective Well-Being. An Interdisciplinary Perspective (International Series in Experimental Social Psychology). Oxford: Pergamon Press.

Iaffaldano, M. T., \& Muchinsky, P. M. (1985). Job Satisfaction and Job Performance: A Meta-Analysis. Psychological Bulletin, 97, 251-273. http://dx.doi.org/10.1037/0033-2909.97.2.251

Inauen, A., Jenny, G., \& Bauer, G. (2015). Discriminating Five Forms of Job Satisfaction: Investigating Their Relevance for Occupational Health Research and Practice. Psychology, 6, 138-150. http://dx.doi.org/10.4236/psych.2015.62013

Jiménez, P. (2000). Job Satisfaction and Burnout from a Cybernetic View-An Integrative Model, First Project-Results. International Journal of Psychology, 35, 309.

Jiménez, P. (2002). Specific Influences of Job Satisfaction and Work Characteristics on the Intention to Quit: Results of Different Studies. Psychologische Beiträge, 44, 596-603.

Jiménez, P. (2006). Arbeitszufriedenheit als Mittlervariable in Feedbackprozessen. Einekybernetische Perspektive (Job Satisfaction as Mediator in Feedback Loops. A Cyberneticview). In L. Fischer (Hrsg.), Arbeitszufriedenheit. Konzepte und empirische Befunde (pp. 160-186). Göttingen: Hogrefe.

Jiménez, P. (2008). PAZ Profilanalyse der Arbeitszufriedenheit. Manual Wiener Testsystem (Profile Analysis of Job Satisfaction. Test Manual in Vienna Test System). Mödling: Schuhfried GmbH.

Jiménez, P., \& Topf, M. (2007). Estimations Regarding the Development of Work Satisfaction. Proceedings of the 10th European Congress of Psychology, Prague, 3-6 July 2007.

Judge, T. A., \& Bono, J. E. (2001). Relationship of Core Self-Evaluations Traits-Self-Esteem, Generalized Self-Efficacy, Locus of Control, and Emotional Stability-With Job Satisfaction and Job Performance: A Meta-Analysis. Journal of Applied Psychology, 86, 80-92. http://dx.doi.org/10.1037/0021-9010.86.1.80

Judge, T. A., Bono, J. E., \& Locke, E. A. (2000). Personality and Job Satisfaction: The Mediating Role of Job Characteristics. Journal of Applied Psychology, 85, 237-249. http://dx.doi.org/10.1037/0021-9010.85.2.237

Judge, T. A., Locke, E. A., Durham, C. C., \& Kluger, A. N. (1998). Dispositional Effects on Job and Life Satisfaction: The Role of Core Evaluations. Journal of Applied Psychology, 83, 17-34. http://dx.doi.org/10.1037/0021-9010.83.1.17

Judge, T. A., \& Larsen, R. J. (2001). Dispositional Affect and Job Satisfaction: A Review and Theoretical Extension. Organizational Behavior and Human Decision Processes, 86, 67-98. http://dx.doi.org/10.1006/obhd.2001.2973

Judge, T. A., Locke, E. A., \& Durham, C. C. (1997). The Dispositional Causes of Job Satisfaction: A Core Evaluations Approach. Research in Organizational Behavior, 19, 151-188.

Judge, T. A., Jackson, C. L., Shaw, J. C., Scott, B. A., \& Rich, B. L. (2007). Self-Efficacy and Work-Related Performance: The Integral Role of Individual Differences. Journal of Applied Psychology, 92, 107-127.

http://dx.doi.org/10.1037/0021-9010.92.1.107

Judge, T. A., Thoresen, C. J., Bono, J. E., \& Patton, G. K. (2001). The Job-Satisfaction-Job Performance Relationship: A Qualitative and Quantitative Review. Psychological Bulletin, 127, 376-407. http://dx.doi.org/10.1037/0033-2909.127.3.376

Kuhl, J. (1990). Kurzanweisung zum Fragebogen HAKEMP 90. Handlungskontrolle nach Erfolg, Misserfolg und prospektiv. Unveröffentlichtes Manuskript, Osnabrück: Universität Osnabrück.

Laux, L., Glanzmann, P., Schaffner, P., \& Spielberger, C. (1981). Das State-Trait-Angstinventar. Theoretische Grundlagen und Handanweisung. Weinheim: Beltz Test GmbH.

Milner, K., Greyling, M., Goetzel, R., Da Silva, R., Kolbe-Alexander, T., Patel, D., Nossel, C., \& Beckowski, M. (2013). The Relationship between Leadership Support, Workplace Health Promotion and Employee Wellbeing in South Africa. Health Promotion International. http://dx.doi.org/10.1093/heapro/dat064

Niklas, C. D., \& Dormann, C. (2005).The Impact of State Affect on Job Satisfaction. European Journal of Work and Organizational Psychology, 14, 367-388. http://dx.doi.org/10.1080/13594320500348880

Parmar, N. R. (2001). Job Anxiety as a Moderator Variable in the Relationship between Job Characteristics and Individual as Well as Organizational Outcomes. Journal of the Indian Academy of Applied Psychology, 27, 75-81.

Roe, R. (2003). Conceptual and Empirical Analysis of the Temporal Dimensions of Organizational Behavior. Proceedings of the 11th European Congress on Work and Organizational Psychology, Lisbon, 14-17 May 2003.

Roe, R. A. (2008). Time in Applied Psychology. The Study of “What Happens” Rather than "What Is.” European Psychologist, 13, 37-52. http://dx.doi.org/10.1027/1016-9040.13.1.37 
Sánchez-Anguita, A., Conde, J., De la Torre, A., \& Pulido, M. F. (2008). Anxiety and Work Satisfaction in Female Healthcare Workers. Ansiedad y Estres, 14, 55-69.

Schermelleh-Engel, K., Moosbrugger, H., \& Müller, H. (2003). Evaluating the Fit of Structural Equation Models: Test of Significance and Descriptive Goodness-of-Fit Measures. Methods of Psychological Research Online, 8, 23-74.

Schumacher, J. (2003). SWLS-Satisfaction with Life Scale. In: J. Schumacher, A. Klaiberg, \& E. Brähler (Hrsg.), Diagnostische Verfahren zu Lebensqualität und Wohlbefinden (pp. 305-309). Göttingen: Hogrefe.

Seligman, M. E. P. (1975). Helplessness: On Depression, Development, and Death. San Francisco, CA: Freeman.

Semmer, N., Baillod, J., Stadler, R., \& Gail, K. (1996). Fluktuation bei Computerfachleuten: Eine Follow-Up Studie. Zeitschrift für Arbeits- und Organisationspsychologie, 40, 190-199.

Spector, P. E. (2000). Industrial and Organizational Psychology: Research and Practice. New York: John Wiley \& Sons, Inc.

Stumpp, T., Muck, P. M., Hülsheger, U. R., Judge, T. A., \& Maier, G. W. (2010). Core Self-Evaluations in Germany: Validation of a German Measure and Its Relationships with Career Success. Applied Psychology: An International Review, 59, 674-700. http://dx.doi.org/10.1111/j.1464-0597.2010.00422.x

Tzeng, H. (2002). The Influence of Nurses’ Working Motivation and Job Satisfaction on Intention to Quit: An Empirical Investigation in Taiwan. International Journal of Nursing Studies, 39, 867-878. http://dx.doi.org/10.1016/S0020-7489(02)00027-5

Van Eerde, W., \& Thierry, H. (1996). Vroom's Expectancy Models and Work-Related Criteria: A Meta-Analysis. Journal of Applied Psychology, 81, 575-586. http://dx.doi.org/10.1037/0021-9010.81.5.575

Vroom, V. H. (1964). Work and Motivation. New York: John Wiley \& Sons.

Wegge, J., Schmidt, K., Parkes, C., \& van Dick, R. (2007). “Taking a Sickie”: Job Satisfaction and Job Involvement as Interactive Predictors of Absenteeism in a Public Organization. Journal of Occupational and Organizational Psychology, 80, 77-89. http://dx.doi.org/10.1348/096317906X99371

West, S., Finch, J. F., \& Curran, P. J. (1995). Structural Equation Models with Nonnormal Variables. In R. H. Hoyle (Ed.), Structural Equation Modeling. Concepts, Issues, and Applications (pp. 56-75). Newbury Park, CA: Sage.

Wright, T. A. (2014). Putting Your Best "Face” Forward: The Role of Emotion-Based Well-Being in Organizational Research. Journal of Organizational Behavior, 35, 1153-1168. http://dx.doi.org/10.1002/job.1967

Wright, T. A., \& Bonnet, D. G. (2007). Job Satisfaction and Psychological Well-Being as Nonadditive Predictors of Workplace Turnover. Journal of Management, 33, 141-160. http://dx.doi.org/10.1177/0149206306297582 